\title{
Physical Education in Primary and Middle Schools from the Perspective of Physical Fitness and Health Monitoring
}

\author{
Yong $\mathrm{Yu}$ \\ Collaborative Innovation Center of Assessment toward \\ Basic Education Quality \\ Beijing Normal University \\ Beijing, China
}

\author{
Youfa $\mathrm{Li}^{*}$ \\ Collaborative Innovation Center of Assessment toward \\ Basic Education Quality \\ Beijing Normal University \\ Beijing, China \\ *Corresponding Author
}

\begin{abstract}
According to the investigation report of 20 years of physical health students in China, primary and middle school students' myopia problem is more and more serious. After 2000, the growth rate has increased. The smaller age group, the more detection rate of myopia increased. The severe myopia is younger. Primary and middle school students' physical health level is short board comprehensive quality all-round development of students. The state and society are gradually conscious of the importance of promoting youth fitness and health, so the state has issued on the policies and regulations of strengthening school physical education to promote comprehensive development of physical and mental health of students. The state pay attention to physical education curriculum (school degree, teachers, time and facilities installed), extracurricular sports, family sports education to strengthen the management of physical education in primary and middle schools from the perspective of physical fitness and health monitoring of primary and middle school,. To help teenagers develop sports interest, to develop a lifelong habit of physical exercise, to promote healthy lifestyles, to grasp the movement technology, to promote the rule and cooperation consciousness and determination of the quality of physical education and health, we must improve teenagers' physical education literacy and comprehensive development.
\end{abstract}

Keywords-physical education; primary and middle schools; physical fitness and health monitoring; management

\section{INTRODUCTION}

Physical education is the weak link of the whole education in China. There are many outstanding problems, insufficient realizing the importance of physical education, the shortage of physical education and extracurricular activities time, no guarantee the shortage of physical education teachers, lack of facilities. Schools physical education evaluation mechanism should be set up. Social force to support the physical education is not enough. The level of students' physical health the quality of the students is still significantly short board.

This research was supported by independent subject of Collaborative Innovation Center of Assessment toward Basic Education Quality, Beijing Normal University in China (BJSP-2016A1-16003).

\section{THE EXAMPLE OF THE DETECTION RATE OF MYOPIA REFLECTS THE PRIMARY AND SECONDARY SCHOOL PHYSICAL HEALTH PROBLEMS SERIOUSLY}

Referring to 1995, 2000, 2005, 2010 and 2014 Chinese students' physique and health survey report [9], [10], [11], [12], [13]; we analyzed the relevant data of myopia detection rate in primary and secondary schools in china. From "Table I" and "Fig. 1" show that Chinese primary and secondary school students' myopia Chinese average detection rate was $38.68 \%$, $39.64 \%, 47.49 \%, 55.05 \%, 57.09 \%$, and $7.85 \%$ from 1995 to 2014. The difference is respectively $0.96 \%, 7.56 \%, 2.04 \%$, each test compared to the last time. The detection rate of myopia has increased, and the detection rate increased after 2000 speed up, that over the past 20 years. More and more myopia problems of primary and secondary school students in our country is very serious, but the increase.

The myopia rate of $7-9,10-12,13-15,16-18$ years old age in 2014 were $30.63 \%, 51.88 \%, 68.97 \%, 77.28 \%, 1995$ of all ages were $14.43 \%, 25.23 \%, 48.90 \%, 66.51 \%$, respectively, an increase of all ages: $112 \%, 108 \%, 41 \%, 16 \%$, account for nearly 20 years. Chinese students of all ages are very serious problem of myopia. The smaller age group, the more detection rate of myopia increased. The severe myopia is younger.

From the difference of "Table I", the age group is 7-9, 10 $12,13-15$ years old age in the primary and secondary school students' myopia detection rate increased significantly of 2000-2010 years. According to the dynamic change curve of "Fig. 1", the increase of 10-12 and 13-15 years old is obviously larger than average after 2000. This shows that the myopia problem of primary and secondary school students in China tends to be younger. The heavy burden of students' academic burden, from senior high school to primary and junior high school, may be an important reason.

In 2014 and 2010 shows that the difference of all ages, the detection rate of myopia growth has slowed, and in 2010 the student physique health test report after the publication of national attention to the eyesight of students health and introduce relevant policies [14], [15], [16]. 
TABle I. Dynamic Changes of Myopia Rate of Primary and Middle School Students in 1995-2014 Years in China $/ \%$

\begin{tabular}{|c|l|l|l|l|l|l|l|l|l|}
\hline Age group & $\mathbf{1 9 9 5}$ & Difference & $\mathbf{2 0 0 0}$ & Difference & $\mathbf{2 0 0 5}$ & Difference & $\mathbf{2 0 1 0}$ & Difference & $\mathbf{2 0 1 4}$ \\
\hline $\mathbf{7 - 9}$ & 14.43 & 1.03 & 15.46 & 7.25 & 22.71 & 7.36 & 30.07 & 0.56 & 30.63 \\
\hline $\mathbf{1 0 - 1 2}$ & 25.23 & -3.39 & 21.84 & 14.73 & 36.57 & 11.04 & 47.61 & 4.27 & 51.88 \\
\hline $\mathbf{1 3 - 1 5}$ & 48.90 & -1.15 & 47.75 & 8.45 & 56.20 & 9.39 & 65.59 & 3.38 & 68.97 \\
\hline $\mathbf{1 6 - 1 8}$ & 66.51 & 4.36 & 70.87 & 3.09 & 73.96 & 3.03 & 76.99 & 0.29 & 77.28 \\
\hline Average & 38.68 & 0.96 & 39.64 & 7.85 & 47.49 & 7.56 & 55.05 & 2.04 & 57.09 \\
\hline
\end{tabular}

a. Note: The "Difference" indicates the difference of myopia rate between the next year and the previous year.

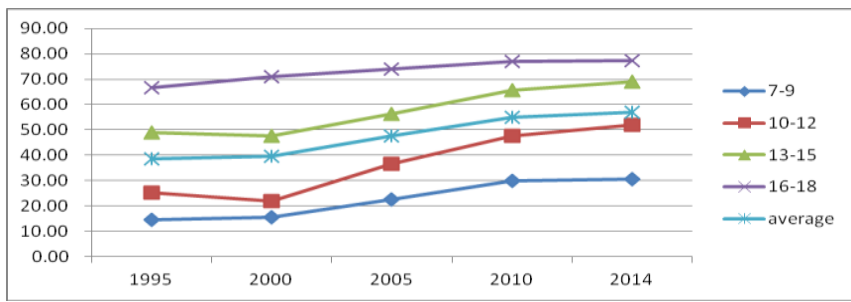

Fig. 1. The dynamic change of myopia rate of primary and middle school students in 1995-2014 years.

\section{PHYSICAL EDUCATION IN PRIMARY AND MIDDLE SCHOOLS FROM THE PERSPECTIVE OF PHYSICAL FITNESS AND HEALTH MONITORING}

Physical education is the most important curriculum in primary and secondary schools, and its distinctive practice and flexible form of classroom organization have attracted great attention from all over the world. All countries will be identified as an excellent course of social development and social training, the curriculum included a lot of interpersonal communication, personality, habits, values, coping style and social setting, content of human and nature and society.

\section{A. The Teaching of School Physical Education Curriculum}

Teaching staff education in our country has taken a series of work, such as "on the strengthening of physical education and promote physical and mental health of students comprehensive development of opinions", "National Fitness Program (2016 - 2020)" and "sports development plan", "13th Five-Year" has repeatedly stressed that the school should pay attention to physical education, quality and quantity to complete the goal of physical education curriculum the requirements of the teaching task on time. In order to cultivate students' interest, develop exercise habits, master sports skills and enhance students' physique as the main line, improve the national sports and health curriculum standards, establish the convergence system of physical education curriculum in primary and secondary schools. Local primary and secondary schools should set up good physical education courses according to the national curriculum and curriculum standards, and strictly prohibit the reduction and crowding out of PE classes. Where conditions permit, sports classes can be added to primary and secondary schools. Institutions of higher learning should offer compulsory courses or elective courses for students. Scientific arrangement of the course content, in the students master the basic sports skills on the basis of, according to the school itself, carry out sports teaching, improve students special sports ability. Vigorously promote the football, basketball, volleyball and other collective projects, and actively promote track and field, swimming, gymnastics and other basic events and ice and snow sports and other special projects, extensive development of table tennis, badminton, martial arts and other advantages of the project. Further excavation and arrangement of folk sports, enrich and enrich the content of sports courses.

\section{B. Extracurricular Sports Activities}

The school carries out extra-curricular sports activities included in the schedule, combined with the teaching contents to the students in the teaching plan, and ensure the students one hour a day on campus sports activities carried out. Kindergarten should follow the characteristics of children's age and physical and mental development, and carry out a variety of sports activities. Primary and secondary schools should organize students to carry out the big break sports activities, and the boarding school should insist on doing morning exercises every day. Colleges and universities should organize students to participate in extracurricular physical exercises in various ways. Vocational schools should pay attention to arranging students' physical training during their internship. Strengthen extracurricular exercises and scientific exercise guidance, mobilize the enthusiasm of family, community and social organizations, and ensure that students exercise for an hour every day. Adhere to cultivate interest and improve skills to promote. Follow the rules of education and sports, guide students with interest, pay attention to teaching students in accordance with their aptitude and participate in happiness, pay attention to the cultivation of motor skills, gradually improve the level of exercise, and lay the foundation for students to develop lifelong physical exercise habits. Adhere to the coordination of group activities and sports competitions. For all students, a wide range of universal sports activities, orderly after-school training and sports competitions, and actively train sports reserve talents, and vigorously build a campus sports culture, and comprehensively improve the physical quality of students.

\section{Family Physical Education}

According to the primary and middle school arrangements for the family "sports operations", Parents must complete quality and quantity. Parents support students to participate in social sports activities, regularly carry out the sunshine sports "series of activities and walked down the network, out of the dormitory, to the playground" theme mass extracurricular physical exercise activities, insist on carrying out an annual student winter long-distance race and other group activities, covering both inside and outside school student extracurricular physical training system. Mobilize the enthusiasm of families, communities and social organizations to ensure that students exercise for an hour a day. These measures are to help young people develop sports interest, develop a lifelong habit of 
physical exercise, promote healthy lifestyles, grasps the movement technology, the promotion of sports and health, enhance the awareness of the rules, the spirit of cooperation and will quality, promote the comprehensive development of young people.

\section{CONCLUSION}

There is no training effect of physical exercise on team organization ability, interpersonal relationship, individual ability and leadership of the doubt, it will be of different age and sex, personality and cultural background of the individual connected together through the internal communication organization members to broaden their horizons, increase social support, psychological benefits such as a sense of belonging. The reasonable way of physical education courses to create specific practical situations to help students find the way of getting along with people, practical manners and etiquette, learn interpersonal skills, so as to promote the comprehensive improvement of individual social cognition, social emotions and social skills. Not only that, New Zealand also expect by physical education students to pay and harvest the experience of life, understand their own ability to control culture, responsible for their own life consciousness, for the future of the initiative to create a happy life, improve their own well-being preparations. This encourages selfmanagement, enhance self-efficacy experience will make students more active in the face of the crisis, setbacks and difficulties when using the coping style, self, instead of complaining, evading responsibility. This kind of positive behavior, once established, will undoubtedly benefit students for life. The goals of self-reliance and self-discipline can also be found in Canada and Ireland, which are embodied in the rational and distribution of exercise time by students. Methods the amount of physical activity from the sports curriculum of middle school students will realize to break up the whole into parts of 30 minutes a day, and try to other aspects of this time management and allocation method to wide in life, to understand life, life goal of teaching management.

\section{REFERENCES}

[1] Ji Xuehui. school physical education management, effectiveness, strategy, [J]. movement, 2013,18:127-128.

[2] Dong Qi. Construct a quality monitoring system for basic education with Chinese characteristics [J]. people's education, 2007 (Z2): 2-3.

[3] State Council. strengthening school sports to promote the health of students all-round development of the views of [E]. issued 2016 Document No. 27.

[4] the State Sports General Administration of sports development. "13th Five-Year" [E]. planning of the State Sports General Administration, 2016,5 .

[5] state department. National Fitness Program (2016 - 2020), [E]., country [2016] 37 document

[6] National Sports General Administration. 2014 National Physical Fitness Monitoring Bulletin [R].2015,11.

[7] paint, Joan. Application of motivation theory in the management of school physical education [J]. literature education (middle), 2010,07:157.

[8] Qian Qian. Since the reform and opening up Chinese thought of physical education management development quiz [J]. intelligence, 2011,23:241.
[9] Chinese student physique and health research group.1995 Chinese student physique and health investigation report [M]. Jilin: Jilin science and Technology Press, 1996: 76-86,200,333-334,400-401.

[10] Chinese student physique and health research group.2000 Chinese student physique and health investigation report [M]. Beijing: Higher Education Press, 2002: 161-171,581-600,765-784.

[11] Chinese student physique and health research group.2005 Chinese student physique and health investigation report $[\mathrm{M}]$. Beijing: Higher Education Press, 2007:103-106,238-244,517-536,728-750.

[12] Chinese student physique and health research group.2010 Chinese student physique and health investigation report [M]. Beijing: Higher Education Press, 2012:171-178,499-518,747-770.

[13] Chinese student physique and health research group.2014 Chinese student physique and health investigation report [M]. Beijing: Higher Education Press, 2016: 163-170,491-510,739-762.

[14] The Office of the Ministry of education, the State Sports Genera Administration Office, office of the Communist Youth League Central Hall. On the fourth session of hundreds of millions of students nationwide sunshine sports winter marathon Activities Notice (teach arts hall 2010 Letter No. 42) [Z].2010.

[15] Ministry of education Circular on the issuance of regulations on the effective guarantee of campus sports activities for primary and secondary school students an hour a day (art, art (2011) No. 2) [Z].2011.

[16] Ministry of education and other fifteen departments on the issuance of the "rural compulsory education student nutrition improvement plan implementation rules" and other five supporting documents notice (Cai Cai [2012]2) [Z].2012. 